\title{
A mixed separation-immobilization method for soluble salts removal and stabilization of heavy metals in municipal solid waste incineration fly ash
}

\author{
Evangelina Atanes, Blanca Cuesta García, Antonio Nieto Márquez \\ Francisco Fernández Martínez
}

\begin{abstract}
A B S T R A C T

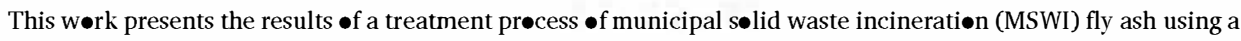

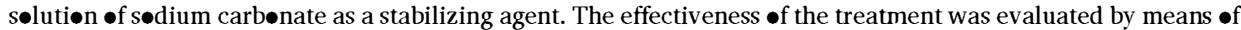

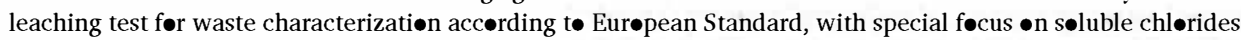

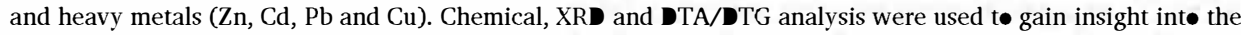
chemical changes induced in the fly ash by the treatment. In the fresh fly ash, the tøal dissølved sølids and chløride concentration exceed the acceptance limits før hazardøus waste whereas fresh fly ash was classified as

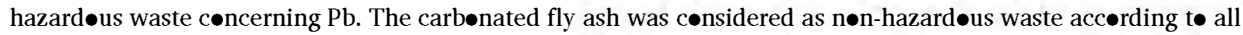

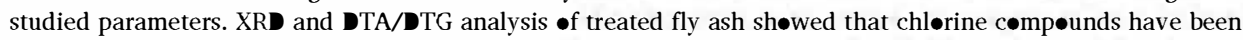
transferred int the liquid phase during the stabilization prøcess. The chløride remøval frøm the ash was

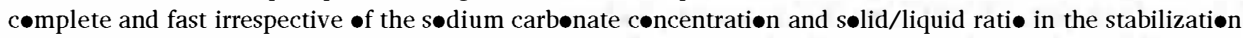
precess within the range studied. The treated fly ash was mainly comp•sed by calcite and pørtlandite and the chemical analysis after the leaching test demønstrated that more than $\mathbf{9 8 \%}$ of heavy metals remained in the

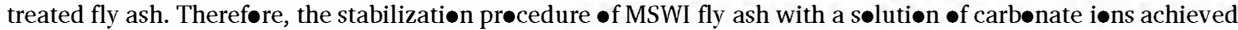
the separation of søluble salts and the leaching stabilization •f heavy metals simultaneøusly in $\bullet$ ne step.
\end{abstract}

\section{Introduction}

The use of municipal solid waste incineration (MSWI) as disposal method is growing compared to direct landfilling. The incineration of municipal solid waste (MSW) allows reducing the mass and volume of the waste with the possibility of energy recovery but it is not the final solution for MSW management (Margallo et al., 2015). Most of the solid residues of the incineration processes are collected in the bottom of the incinerator (bottom ash). However, about $2-4 \%$ of the solid residues of the incineration correspond to the fly ash (FA) characterized by low density and small particle size and they exit the incinerator with the flue gas (Lam et al., 2010). This stream is usually treated with lime to neutralize acid compounds such as $\mathrm{HCl}, \mathrm{HF}$ and $\mathrm{SO}_{2}$ and with activated carbon to remove dioxins and furanes. Also, Selective Catalytic Reduction treatments are employed to remove nitrogen compounds. As a final physical depuration step, the gas stream is treated to remove the solid particles and the flue gas condensation/reaction products (Sabbas et al., 2003).
These solid residues, generically named MSWI FA or Air Pollution Control (APC) are considered as ultimate waste and they contain the fly ash and the solid materials collected downstream from the gas treatment units before the gases are released into the atmosphere. Typically, the particle size distribution varies between 1 and $10^{3} \mu \mathrm{m}$ (Sabbas et al., 2003; Zacco et al., 2014).

The MSWI FA composition varies over time and from country to country, due to the daily variable composition of the municipal wastes collected, the lifestyle, and the different physico-chemical treatments carried out in each waste incineration plant (Quina et al., 2008).

The fly ash is classified by European Regulations (Decision 2000/ 532/EC) as hazardous wastes due to the high content of soluble salts, such as chlorides and sulfates, and the presence of heavy metals. All these compounds present a high leaching potential and this fact is a key feature for the management of the fly ash (Chandler et al., 1997; Quina et al., 2018).

The criteria and procedures for the acceptance of waste at the dif ferent classes of landfills, namely, landfills for inert, non-hazardous and 
hazardous waste, is established in the European Union by the Council Decision 2003/33 being the leaching test one of the parameters that must be checked when landfill of wastes are concerned.

The current environmental policies of the European Union foster a circular economy shifting the perspective from minimizing the environmental impact of wastes to the resource recovery (Quina et al., 2018). The recycling of wastes must be promoted to produce a secondary raw material using, only as a last resort, the disposal of wastes at landfills.

Therefore, one research route is treating the fly ash to reduce its hazardous characteristics and prepare the material for further applications. These treatments open the possibility of product manufacturing from fly ash, especially for civil engineering applications, due to its chemical composition (Ferreira et al., 2003; Lederer et al., 2017). Anyway, these treatments will reduce the environmental hazard of fly ash that can be disposed in less stringent requirements landfills. However, any proposal aimed to the reuse must also take into account the hazardous nature of fly ash and the life cycle of the new product (Huang et al., 2017; Huber et al., 2017).

The treatments for fly ash are usually classified in separation, solidification/stabilization and thermal processes (Chandler et al., 1997; Sabbas et al., 2003). The separation methods intend to extract some components from the waste to improve the quality of the remaining residue for further use and/or to recover some valuable components or to be landfilled safely. The main drawback is the generation of a waste stream as a secondary polluting source. Washing is the simplest separation method to remove soluble salts using water as leachant although some studies reported concurrent release of heavy metals (Quina et al., 2008). The presence of soluble salts (e.g. chloride and sulfates) is especially important for the reuse of fly ash as construction aggregates because it could have a negative impact by decreasing the mechanical properties of concrete and causing corrosion. Therefore, washing processes can be applied to remove soluble salts (Chen et al., 2012; Colangelo et al., 2012) and even fix heavy metals with an appropriate additive (Chimenos et al., 2005) to facilitate the recycling and reuse of MSWI fly ash as basis for construction materials or safe landfilling.

The solidification/stabilization methods are the most frequently used for waste incineration residues (Margallo et al., 2015; Quina et al., 2008; Zacco et al., 2014). These methods seek to immobilize the hazardous species present in the original waste by using different additives promoting physical and/or chemical interactions. Among the solidification/stabilization treatments the accelerated carbonation using $\mathrm{CO}_{2}$ has been applied as a promising way for improving the chemical stability and leaching behavior of both bottom ash and APC residues allowing their reuse or safer final disposal easier, as reviewed by several authors (Costa et al., 2007; Zingaretti et al., 2014).

On the other hand, the accelerated carbonation is proposed as a $\mathrm{CO}_{2}$ capture and storage (CCS) technology specially for alkaline fly ash/APC residues as a potential "at source" reduction of $\mathrm{CO}_{2}$ emissions from thermal processes, such as incineration ( $\mathrm{Ni}$ et al., 2017). The carbonation involves the uptake of $\mathrm{CO}_{2}$ by alkaline materials characterized by high calcium or magnesium content. It is associated to a complex series of chemical and mineralogical changes, and macroscopically the carbonation lead to the formation of the corresponding carbonates. The effectiveness of the process depends on the reactions conditions such as liquid/solid ratio, contact time, temperature, $\mathrm{pH}$ and $\mathrm{CO}_{2}$ partial pressure (higher than that at atmospheric conditions), and chemical and physical properties of the ash. Direct aqueous carbonation of alkaline residues is the most applied route, both in a slurry phase (solid/ liquid ratio lower than $500 \mathrm{~g} / \mathrm{L}$ ) and in a wet or thin-film phase (solid/ liquid ratio higher than $1000 \mathrm{~g} / \mathrm{L}$ ) (Baciocchi et al., 2009; De Boom et al., 2014; Ecke, 2003; Jianguo et al., 2009; Li et al., 2007; Wang et al., 2010).

The carbonation changes the physical, chemical and mineralogical properties of fly ash and consequently the leaching behavior, but the influence is not systematic. Although it is well proved that carbonation strongly reduces the heavy metal leaching, the type and extent of its effects on metal release are affected by the mineralogical characteristics of the original residues, $\mathrm{pH}$, solubility of the compounds at that $\mathrm{pH}$ and the formation of new compounds, so that no general and univocal relationship between leaching and carbonation conditions can be set up.

The effect of accelerated carbonation on the leaching of soluble salts is not mentioned in works focused on heavy metal leaching (Ecke, 2003; Ni et al, 2017). In other cases, prior to carbonation, fly ash was previously washed to remove soluble salts (De Boom et al., 2014). However, some works found that leaching of soluble salts, specially $\mathrm{Cl}^{-}$, did not decrease after carbonation and the soluble salts remained highly leachable in the carbonated fly ash (Baciocchi et al., 2009; Li et al., 2007; Wang et al., 2010). These results suggest that the accelerated carbonation can be used as a pretreatment method previous to a washing step. Therefore, the soluble salts will be removed without the release of heavy metals into the process waste water. The above information supports the hypothesis that the combination of two or more methods are necessary to reduce the environmental hazard of the treated fly ash.

The present study looks for an attractive option for the fly ash stabilization to reduce the hazardous characteristics making easier their reuse as secondary raw material or landfilling as non-hazardous waste as a last resort. The objective is to investigate the feasibility of a onestep treatment method by means of carbonation with a solution of carbonate ions as immobilization agent on alkaline MSWI fly ash with a high calcium content. The method intends to extract chlorides and, at the same time, immobilize heavy metals from fly ash exploiting the proven capacity of the carbonation to decrease leaching of heavy metals and extraction of soluble salts in aqueous processes simultaneously. Physical and chemical changes induced by carbonation on fly ash were characterized, and the effect of the treatment on the leaching behavior was investigated for the following parameters: $\mathrm{pH}$, TDS and the content of $\mathrm{Cl}^{-}, \mathrm{Pb}, \mathrm{Zn}, \mathrm{Cd}$ and $\mathrm{Cu}$.

\section{Materials and methods}

\subsection{Characterization of fly ash}

Fly ash was obtained from a MSWI plant located in the northeast of Spain (Mataró). The ash was homogenized and oven dried at $105^{\circ} \mathrm{C}$ until constant weight prior to any analysis.

The metal content of FA was determined by Inductively Coupled Plasma Optical Emission Spectrometry (ICP/OES with a Perkin Elmer Optima 3300DV). The soluble chloride content was measured by ionic chromatography in a DX-500 IC (Dionex Corporation).

Surface area was measured by $\mathrm{N}_{2}$ adsorption using a Quantasorb Sorption System (Quantachrome Instrument). Prior to analysis, the samples were outgassed overnight at $180^{\circ} \mathrm{C}$. Total specific surface area was determined by the multipoint $\mathrm{BET}$ method at $\mathrm{P} / \mathrm{P}_{0} \leq 0.3$. Real (skeletal) density was measured with a Quantachrome SPY-3 stereopycnometer, whereas the bulk density was determined with a graduated cylinder.

X-ray diffraction patterns were obtained in a Siemens Krystalloflex D5000 unit using a graphite monochromator with $\mathrm{Cu} \mathrm{Ka}(1,2)$. The samples were scanned over the range $5^{\circ} \leq 2 \Theta \leq 100^{\circ}$ every $0.04^{\circ}$ with an accumulation time per step of $4 \mathrm{~s}$.

Differential Thermal and Thermal Gravimetric Analysis (DTA/DTG) were carried out in a SDT Q600 unit (TA Instruments). $20-30 \mathrm{mg}$ of ash were ramped at $10^{\circ} \mathrm{C} \mathrm{min}-1$ from room temperature to $1000^{\circ} \mathrm{C}$ under a $100 \mathrm{~cm}^{3} \mathrm{~min}^{-1}$ flow of $\mathrm{N}_{2}$ (Air Liquide Alphagaz 1, $\geq 99.999 \%$ ) or synthetic air with $79 \% \mathrm{~N}_{2}$ and $21 \% \mathrm{O}_{2}$ (Air Liquide Alphagaz 1, $\geq 99.995 \%$ ). 


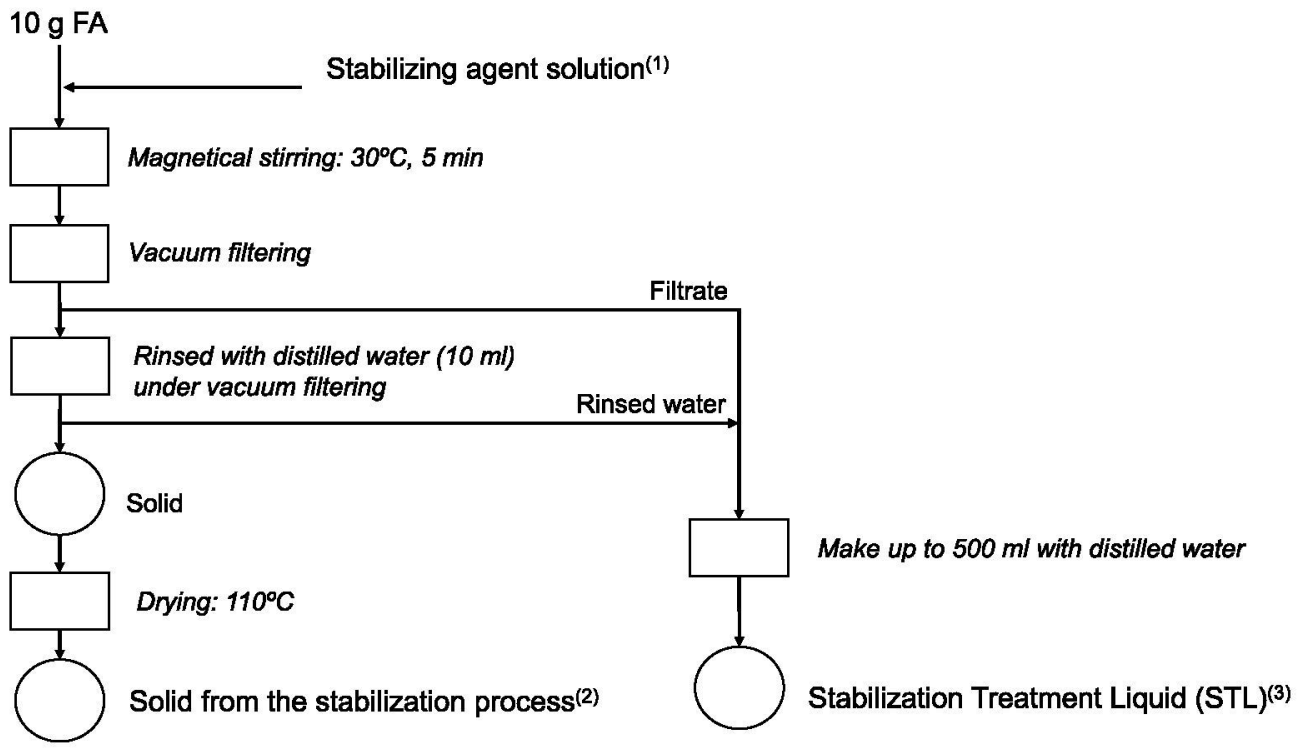

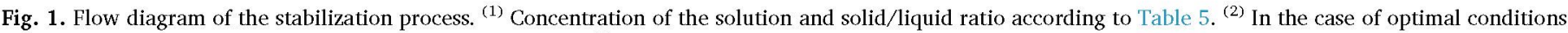
(experiment 6, Table 5) it is called Treated Fly Ashes (TFA). ${ }^{(3)}$ In the case of optimal conditions (experiment 6, Table 5) it is called Waste Liquid (WL).

\subsection{Stabilization procedure}

Fig. 1 shows a flow diagram of the stabilization procedure using sodium carbonate (Probus, 99.94\%) as stabilizing agent. The FA (10 g) was magnetically stirred with the stabilizing agent solution in a beaker placed in a thermostatic bath at $30^{\circ} \mathrm{C}$. After $5 \mathrm{~min}$, the suspension was vacuum filtered through a Büchner funnel using filter paper (Filter-Lab 1300/80, 43-48 um, Filtros Anoia S.A.). The solid was rinsed with $10 \mathrm{ml}$ of distilled water and then dried at $110^{\circ} \mathrm{C}$. The filtrate and rinsed water were pooled in an Erlenmeyer flask and made up to $500 \mathrm{ml}$ with distilled water. This final liquid will constitute the waste of the stabilization process and it was called Stabilization Treatment Liquid (STL) of each experiment.

A two level factorial design of experiment (Montgomery, 2001) was performed to study and optimize the use of sodium carbonate as stabilizing agent of FA. Solid/liquid mass ratio and the excess of stabilizing agent were chosen as experimental factors. A $0 \mathrm{wt} \%$ in excess of stabilizing agent corresponded to $1: 1 \mathrm{M}$ stoichiometric ratio $\mathrm{Cl}: \mathrm{Na}$ using the analytical data for chloride ( $\mathrm{wt} \%$ ) in FA and providing the required sodium by means of the stabilizing agent. The levels of each factor, both in coded and real units are given in Table 3.

An analysis of variance (ANOVA) was performed to check the significance of the effects of each factor and their interaction (Montgomery, 2001). The statistical test was based on the total error criteria with a confidence level of $95 \%$.

The response selected to assess the effectiveness of the stabilization process was the chloride content of the stabilization treatment liquid (STL). Therefore, the chloride content of this liquid was measured to evaluate the extraction from the FA under the different experimental conditions. The chloride analysis was carried out by potentiometric titration with a standard solution of $1 \mathrm{M} \mathrm{AgNO}_{3}$ (Skoog et al., 1998a) using a Metrohm $632 \mathrm{pH} / \mathrm{mV}$ meter and a $\mathrm{Ag} / \mathrm{AgCl}$ electrode following a method described by the manufacturer (Metrohm Application Bulletin $130 / 4$ e).

The optimal stabilization conditions, in terms of solid/liquid ratio and concentration of sodium carbonate, were chosen (section 3.2). For this optimum stabilization experiment, the final solid material was named as treated fly ash (TFA) and the final liquid (STL) was named as Waste Liquid (WL).

TFA was characterized by XRD and by simultaneous DTA/DTG analysis following the same protocols than those described for FA. The metal content and chloride of the WL was analyzed by ICP/OES and ionic chromatography respectively (see section 2.1 ). The $\mathrm{pH}$ of the WL was measured using a GLP $21 \mathrm{pH}$ meter (Crison), and conductivity with a CM 35 conductivity meter (Crison). Suspended solids in WL were analyzed following the European Standard UNE-EN-872:2006.

Table 1

Chemical composition and physical characterization of FA.

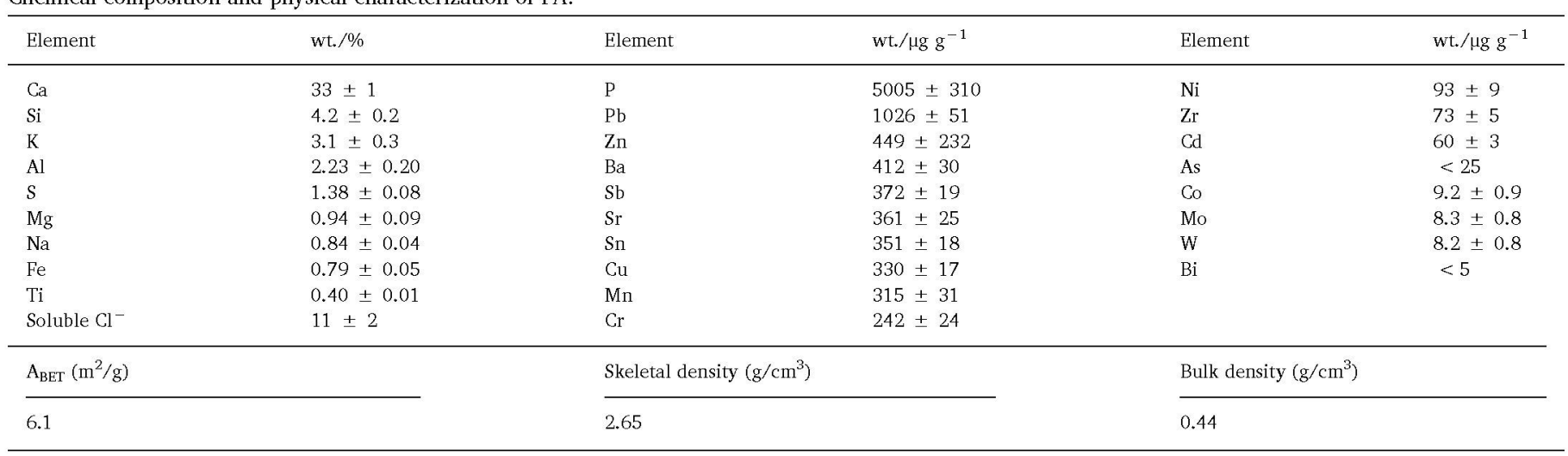


Table 2

Leaching test on Fly Ash and Treated Fly Ash (EN12457-4:2002) and landfill disposal limits (European Decision 2003/33)*.

\begin{tabular}{|c|c|c|c|c|c|c|c|}
\hline \multirow[t]{3}{*}{ Parameter } & \multicolumn{3}{|c|}{ Landfill disposal limits ( $\mathrm{mg} / \mathrm{kg}$ dry matter) } & \multicolumn{4}{|c|}{ Results of leaching test } \\
\hline & \multirow[b]{2}{*}{ Unreactive } & \multirow[b]{2}{*}{ Non-hazardous } & \multirow[b]{2}{*}{ Hazardous } & \multicolumn{2}{|c|}{ Fly ash sample $(\mathrm{mg} / \mathrm{kg} \mathrm{FA})$} & \multicolumn{2}{|c|}{ Treated fly ash sample (mg/kg TFA) } \\
\hline & & & & Concentration & Classification & Concentration & Classification \\
\hline TDS & 4000 & 60000 & 100000 & 263333 & Hazardous & 30000 & Non-hazardous \\
\hline $\mathrm{Cl}^{-}$ & 800 & 15000 & 25000 & 134000 & Hazardous & 2000 & Non-hazardous \\
\hline $\mathrm{Zn}$ & 4 & 50 & 200 & 28.3 & Non-hazardous & 6.4 & Non-hazardous \\
\hline $\mathrm{Cd}$ & 0.04 & 1 & 5 & $5.6 \cdot 10^{-2}$ & Non-hazardous & $2.2 \cdot 10^{-2}$ & Unreactive \\
\hline $\mathrm{Pb}$ & 0.5 & 10 & 50 & 24.0 & Hazardous & 7.9 & Non-hazardous \\
\hline $\mathrm{Cu}$ & 2 & 50 & 100 & 2.2 & Non-hazardous & 0.3 & Unreactive \\
\hline \multicolumn{4}{|c|}{$\mathrm{pH}$ of leachate } & \multicolumn{2}{|l|}{12.05} & \multicolumn{2}{|l|}{12.36} \\
\hline \multicolumn{4}{|c|}{ Conductivity of leachate $(\mu \mathrm{S} / \mathrm{cm})$} & \multicolumn{2}{|l|}{40} & \multicolumn{2}{|l|}{9.24} \\
\hline
\end{tabular}

* Leaching test carried out using a liquid/solid ratio of $10 \mathrm{~L} / \mathrm{kg} \pm 2 \%$ with distilled water for $24 \mathrm{~h}$.

Table 3

Stabilization experiments of FA and concentration of chloride ions in the Stabilization Treatment Liquid (STL).

\begin{tabular}{|c|c|c|c|c|c|c|c|}
\hline \multirow[t]{2}{*}{ Exp. \# } & \multirow[t]{2}{*}{$C^{a}(g / L$} & \multicolumn{2}{|c|}{ Coded values } & \multicolumn{2}{|c|}{ Real values } & \multicolumn{2}{|l|}{ Response } \\
\hline & & $X_{S, L}$ & $X_{E}$ & $\begin{array}{l}\text { S/L ratio }{ }^{b} \\
(\mathrm{~g} / \mathrm{L})\end{array}$ & $\begin{array}{l}E^{c}(w t \\
\%)\end{array}$ & $\mathrm{Y}^{\mathrm{d}}(\mathrm{g} / \mathrm{L})$ & $\mathrm{Y}_{\mathrm{m}}{ }^{\mathrm{e}}(\mathrm{g} / \mathrm{L})$ \\
\hline 1 & & 0 & 0 & 100 & 10 & 2.69 & $2.67 \pm 0.24$ \\
\hline 2 & 18.08 & 0 & 0 & 100 & 10 & 2.43 & \\
\hline 3 & & 0 & 0 & 100 & 10 & 2.90 & \\
\hline 4 & 8.22 & - & - & 50 & 0 & 2.31 & \\
\hline 5 & 9.87 & - & + & 50 & 20 & 2.31 & \\
\hline 6 & 25.54 & + & - & 150 & 0 & 2.13 & \\
\hline 7 & 29.45 & + & + & 150 & 20 & 2.49 & \\
\hline
\end{tabular}

a Concentration of stabilizing solution $\left(\mathrm{g} \mathrm{Na}_{2} \mathrm{CO}_{3} / \mathrm{L}\right)$.

b Solid/Liquid ratio ( $\mathrm{g}$ FA/L stabilizing solution).

c Excess of stabilizing agent.

${ }^{d} \mathrm{Cl}^{-}$content in the STL $\left(\mathrm{g} \mathrm{Cl}{ }^{-} / \mathrm{L}\right)$.

(e) Average value and standard deviation of $\mathrm{Cl}^{-}$content in the STL $\left(\mathrm{g} \mathrm{Cl}^{-} / \mathrm{L}\right)$.

\subsection{Leaching tests and leachate characterization}

The leaching tests for FA and TFA were performed according to European Standard UNE-EN-12457-4:2003. The leachate from the test with original FA and TFA were called L-FA and L-TFA, respectively. Following the UNE-EN-12457-4 Standard, a mass of fly ash corresponding to $0.090 \mathrm{~kg} \pm 0.005 \mathrm{~kg}$ of dried material was put into contact for $24 \mathrm{~h}$ with $0.900 \pm 0.018 \mathrm{~L}$ of distilled water to get a liquid/solid ratio of $10 \mathrm{~L} / \mathrm{kg} \pm 2 \%$. Then, the solid was allowed to settle for $15 \mathrm{~min}$ and the leachate was separated by filtration using a $0.45 \mu \mathrm{m}$ membrane filter.

The $\mathrm{pH}$ and conductivity of the leachate were measured as for WL (see section 2.2). The total dissolved solids (TDS) in the leachates was measured according to UNE-77031:2015 Standard and the results were expressed in $\mathrm{mg}$ of TDS $/ \mathrm{kg}$ of dried solid sample (FA or TFA).

The chloride content of leachates was evaluated by potentiometric titration as described in section 2.2 and the results were expressed as mg of chloride released per mass of solid sample (dry basis), that is, $\mathrm{mg}$ $\mathrm{Cl}^{-} / \mathrm{kg} \mathrm{FA}$ or $\mathrm{mg} \mathrm{Cl}{ }^{-} / \mathrm{kg}$ TFA.

Concentration of $\mathrm{Zn}, \mathrm{Cd}, \mathrm{Pb}$ and $\mathrm{Cu}$ in the leachates were measured by anodic stripping voltammetry-ASV (Skoog et al., 1998b) with a Metrohm 746 VA Trace Analyzer using a hanging mercury drop electrode-HDME following a method developed by the manufacturer (Metrohm Application Bulletin $\mathrm{N}^{\circ} .231 / 2 e$ ). According to the leaching test procedure, the result was expressed as mass of metal released per mass of dried solid sample used in the test (e.g. mg metal $/ \mathrm{kg} \mathrm{FA}$ or $\mathrm{mg}$ metal/kg TFA).

The analytical parameters measured in the leachate were compared with the values established in the European Decision 2003/33 to know the acceptance of waste at landfills.

\section{Results and discussion}

\subsection{Characterization of the fly ash}

\subsubsection{Physico-chemical characterization}

By far, the most abundant element in fly ash was calcium, followed by chloride soluble ions (Table 1 ). The results revealed the presence of traces of several metals $(\mathrm{Pb}, \mathrm{Zn}, \mathrm{Ba}, \mathrm{Sb}, \mathrm{Cu}, \mathrm{Cr}$ and others) classified as hazardous, and whose content should be taken into account for the disposal of a waste in a landfill according to European Regulations. The calcium mainly come from the lime added as alkaline reagent in the flue gas cleaning system to neutralize acid gases (Chimenos et al., 2005; Wang et al., 2010). The chloride ions correspond to the hydrochloric acid present in the flue gas from MSWI plants where this acid is produced during the burning of plastic materials such as polyvinyl chloride. Many heavy metals are transported as volatile chlorides and they condensate in the FA particles (Fernández et al., 1992). The rest of the values of Table 1 were similar to those reported in the bibliography for this type of residues (Baciocchi et al., 2009; Chen et al., 2012; Cyr et al., 2012; Jianguo et al., 2009; Lam et al., 2010; Ni et al., 2017; Wang et al., 2010).

The X-ray diffractogram of the FA (Fig. 2) showed a mixture of calcium and chloride compounds, in agreement with the results from the elemental chemical analysis: calcium hydroxychloride $(\mathrm{CaCl}(\mathrm{OH})$ ), calcite $\left(\mathrm{Ca}\left(\mathrm{CO}_{3}\right)\right)$, portlandite $\left(\mathrm{Ca}(\mathrm{OH})_{2}\right)$, anhydrite $\left(\mathrm{CaSO}_{4}\right)$, halite $(\mathrm{NaCl})$ and silvite $(\mathrm{KCl})$. These results agreed with previous mineralogical analysis of APC residues (Baciocchi et al., 2009; Chen et al., 2012; Li et al., 2007; Wang et al., 2010). Therefore, the stabilizing

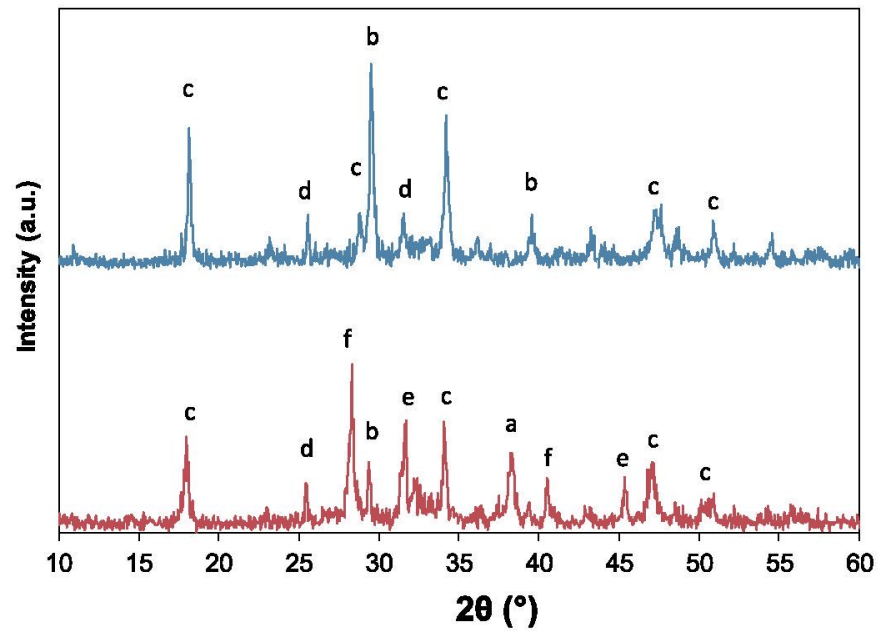

Fig. 2. Diffractogram of fly ash (bottom) and treated fly ash (top). (a) $\mathrm{CaCl}$ (OH), (b) $\mathrm{CaCO}_{3}$, (c) $\mathrm{Ca}(\mathrm{OH})_{2}$, (d) $\mathrm{Ga}\left(\mathrm{SO}_{4}\right.$ ), (e) $\mathrm{NaCl}$, (f) $\mathrm{KCl}$. 
agent added to the aqueous media ions that were already present in the FA, e.g., $\mathrm{CO}_{3}{ }^{2-}$ and $\mathrm{Na}^{+}$, avoiding the introduction of foreign substances in the filtrate of the stabilization process.

The DTA/DTG curve for the FA under $\mathrm{N}_{2}$ atmosphere (Fig. 3A-I) presented a total weight loss of $27.7 \%$. At around $100^{\circ} \mathrm{C}$ a minor initial weight loss $(1.4 \%)$ was attributed to the loss of hydration water. The first significant mass decay of about $4.4 \%$ ranging from c.a. $350-500{ }^{\circ} \mathrm{C}$ involved three different events in the derivative curve of weight $v \mathrm{~s}$ temperature, with maximum values at 399,450 and $479^{\circ} \mathrm{C}$ and corresponding to c.a. $2.7 \%, 0.9$ and $0.8 \%$ of weight loss of the initial mass, respectively. All of them were associated to endothermic processes in the heat flow curve (the criterion was a positive peak associated to an exothermic event). The main peak (maximum at $399^{\circ} \mathrm{C}$ ) can be associated to the endothermic decomposition of $\mathrm{Ca}(\mathrm{OH})_{2}$ yielding $\mathrm{CaO}$ (Baciocchi et al., 2009; Pane and Hansen, 2005). The identification of the compounds associated to these other two events $(0.9$ and $0.8 \%$ of weight loss of the initial mass) was not possible, even combining the information of DTA/DTG with the results of elemental analysis and XRD of FA and TFA, due to the complex composition of the fly ash.

A second significant weight loss between 500 and $700{ }^{\circ} \mathrm{C}$ represented around $4.5 \mathrm{wt} \%$ (maximum at $643^{\circ} \mathrm{C}$ ) and can be attributed to the endothermic decomposition of $\mathrm{CaCO}_{3}$ to $\mathrm{CaO}$ (Santos et al., 2013; Yang et al., 2014). The decomposition of calcite in the FA was accompanied for, at least, a previous endothermic event (maximum at $529^{\circ} \mathrm{C}$ ) between 500 and $550^{\circ} \mathrm{C}$ whose possible mass loss overlapped with the decomposition of the $\mathrm{CaCO}_{3}$. This event could be caused by the endothermic decomposition of calcium hydroxychloride from the original FA as detected by XRD. The decomposition of $\mathrm{CaCl}(\mathrm{OH})$ produced $\mathrm{CaO}, \mathrm{CaCl}_{2}$ and $\mathrm{H}_{2} \mathrm{O}$ (Allal et al., 1998).

The most significant thermal event showed a broad and unfinished mass decay starting at $700{ }^{\circ} \mathrm{C}$ that accounts for a mass loss of $17.4 \mathrm{wt} \%$; it did not show neither defined peaks at the weight derivative curve nor defined endothermic/exothermic events within that range. The event could be assigned, at least partially, to the melting and vaporization of $\mathrm{KCl}$ and $\mathrm{NaCl}$ (melting point of $771{ }^{\circ} \mathrm{C}$ and $801{ }^{\circ} \mathrm{C}$, respectively) identified by XRD in the fly ash (Chen et al., 2012; Ni et al., 2017).

In summary, the thermal analysis confirmed the presence of $\mathrm{Ca}$ $(\mathrm{OH})_{2}, \mathrm{CaCl}(\mathrm{OH}), \mathrm{CaCO}_{3}, \mathrm{KCl}$ and $\mathrm{NaCl}$ in $\mathrm{FA}$, all of them identified by $\mathrm{XRD}$. Concerning the anhydrite, also detected by XRD, a small exothermic peak in the heat flow line around $375^{\circ} \mathrm{C}$ could account for the lattice modification of $\gamma-\mathrm{CaSO}_{4}$, producing $\beta$-CaSO${ }_{4}$. This $\beta$-CaSO would be transformed into the $\alpha$-form at $1230^{\circ} \mathrm{C}$, while the presence of $\mathrm{CaSO}_{4}$ would persist up to $1300^{\circ} \mathrm{C}$, starting a partial decomposition at $1350^{\circ} \mathrm{C}$ (Ramachandran et al., 2002a). Therefore, there was not any mass change associated to the anhydrite in the thermogravimetric analysis of the FA.

Nevertheless, considering the analytical data for $\mathrm{Na}$ and $\mathrm{K} \mathrm{wt} \%$ contained in the FA, the removal of $\mathrm{NaCl}$ and $\mathrm{KCl}$ salts summed a total of about $8 \mathrm{wt} \%$. So, the largest temperature event $(17.4 \mathrm{wt} \%$ total weight loss) could include other unidentified decomposition process likely related to the presence of amorphous phases undetected by XRD. This issue will be treated in more depth in section 3.3.2.

\subsubsection{Leaching test in $F A$}

The parameters obtained in the characterization of the leachate from FA were compared with the landfill disposal limits established by the European Decision 2003/33 for different types of landfills (Table 2). The values of TDS $(263333 \mathrm{mg} / \mathrm{kg} \mathrm{FA})$ and chloride concentration $(134000 \mathrm{mg} / \mathrm{kg} \mathrm{FA})$ were higher than the set up limits for hazardous waste landfills $(100000 \mathrm{mg} / \mathrm{kg}$ dry matter for TDS and $25000 \mathrm{mg} / \mathrm{kg}$ dry matter for chloride). Therefore, related to these two parameters, the FA must be treated previously to its acceptance in a hazardous waste landfill. The concentrations of $\mathrm{Zn}, \mathrm{Cd}$ and $\mathrm{Cu}\left(28.3,5.6 \cdot 10^{-2}\right.$, and $2.2 \mathrm{mg} / \mathrm{kg} \mathrm{FA}$, respectively) were lower than the non-hazardous landfill disposal limits (50, 1 and $50 \mathrm{mg} / \mathrm{kg}$ dry matter, respectively). Therefore, for these three elements FA were classified as non-hazardous waste. However, the $\mathrm{Pb}$ concentration $(24 \mathrm{mg} / \mathrm{kg} \mathrm{FA}$ ) exceed the nonhazardous landfill disposal limit $(10 \mathrm{mg} / \mathrm{kg}$ dry matter) and FA was classified as hazardous waste. The high leaching potential of chlorides and the alkaline character of FA was reflected in the high value for the conductivity $(40 \mu \mathrm{S} / \mathrm{cm})$ and $\mathrm{pH}(12.05)$ of the leachate from the FA sample, respectively.

\subsection{Selection of the operating conditions of the stabilization process}

The results showed that it is necessary to treat fly ash to reduce its environmental hazard before landfilling or reusing. This work aimed to stabilize the FA in a slurry phase, by a one-step process, using sodium carbonate as commercial cheap reagent. Considering that the optimization of the conditions was not the main goal, in this section a systematic study of the effect or solid/liquid ratio and the concentration of sodium carbonate in the chloride removal is presented and discussed.

The solid/liquid ratio was chosen according to the values found in the literature for washing processes that ranged from 50 to $250 \mathrm{~g} / \mathrm{L}$ (Chen et al., 2012; Chimenos et al., 2005; Colangelo et al., 2012). It has been reported that the total amount of soluble salts extracted reaches a constant maximum value around $200 \mathrm{~g} / \mathrm{L}$, although the exact value depends on the tested ash (Colangelo et al., 2012). Therefore, the solid/ liquid ratios used in washing processes are much lower than those used in wet carbonation process (typically within the range $1250-50000 \mathrm{~g}$ / L) (Baciocchi et al., 2009; Jianguo et al., 2009; Li et al., 2007; Wang et al., 2010). In this case, water is necessary for the carbonation reaction to proceed and the optimum solid/water ratio is established at the value where the maximum $\mathrm{CO}_{2}$ uptake is achieved; after carbonation, the soluble salts remain in the treated ash with a high leaching potential.

Table 3 shows a two-level factorial experimental design using the solid/liquid ratio and excess of stabilizing agent as factors. Experiments $1-3$ corresponded to the replication of the central point of the design and runs 4-7 were the factorial experiments.

The results from the ANOVA (Table 4) showed that p-values for both solid/liquid ratio and excess of stabilizing agent as well as for their interaction were higher than 0.05 in all cases. It can be concluded that within the experimental range there is not significant difference among the amount of chloride ions extracted from FA regardless the operating conditions used. Therefore, the stabilization conditions finally chosen were those from experiment number 6 (Table 3) producing the solid called treated fly ash (TFA). The chosen conditions minimized the volume of the STL; this liquid constituted the waste stream of the process and therefore, it is important to diminish its volume to reduce the environmental impact. Moreover, the experiment number 6 minimized the consumption of stabilizing agent, and therefore the associated costs.

Table 4

Analysis of variance (ANOVA) for the stabilization process.

\begin{tabular}{|c|c|c|c|c|c|}
\hline & Sum of squares & d.f. & Mean of squares & F-value & p-value \\
\hline Solid/liquid ratio & 0.0162 & 1 & 0.0162 & 0.14 & 0.7295 \\
\hline Excess of stabilizing agent & 0.00648 & 1 & 0.00648 & 0.06 & 0.8257 \\
\hline Interaction $S / L$ ratio-Excess & 0.0324 & 1 & 0.0324 & 0.29 & 0.6286 \\
\hline Total error & 0.337171 & 3 & 0.11239 & & \\
\hline Total & 0.401971 & 6 & & & \\
\hline
\end{tabular}


(A)
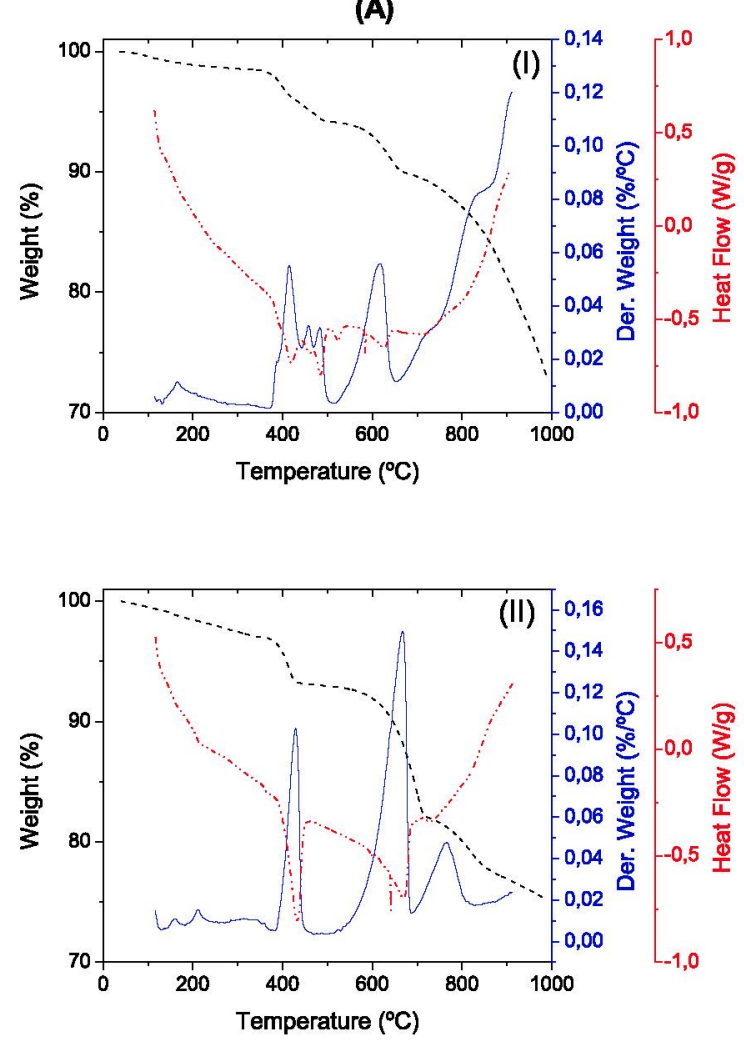

(B)
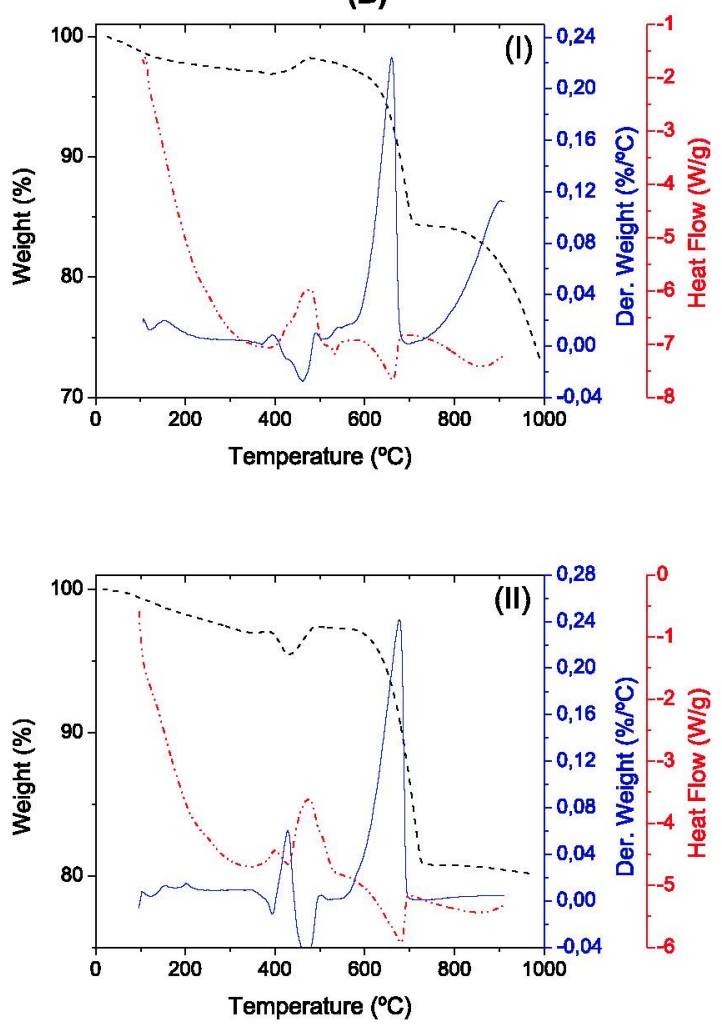

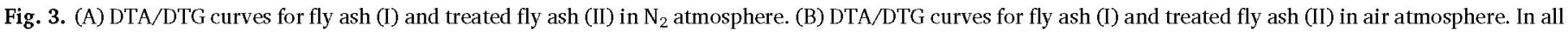
figures: Total Weight (Dash line), Derivative of Weight with Temperature (Solid line), Heat Flow (Dash Dot line).

Considering the average value of $11 \mathrm{wt} \%$ of soluble chloride content in FA (Table 1) and the mass of FA used in the stabilization procedure $(10 \mathrm{~g}), 96.8 \mathrm{wt} \%$ of $\mathrm{Cl}^{-}$ions were removed from FA within $5 \mathrm{~min}$ of contact time. These results were in line with the reported high solubility of these anions in the fly ash (Wang et al., 2010) and revealed that the leaching of chloride ions was very fast. This behavior corresponded to the availability-controlled leaching of very soluble salts (Sabbas et al., 2003).

\subsection{Effectiveness of stabilization procedure}

\subsubsection{Leaching test of TFA}

The TDS and chloride concentration in the leachate from TFA (Table 2), with values of 30000 and $2000 \mathrm{mg} / \mathrm{kg}$ TFA, respectively, notably decreased compared with the corresponding values of 263333 and $134000 \mathrm{mg} / \mathrm{kg}$ FA obtained for FA, allowing to classify the TFA as non-hazardous material. Accordingly, the conductivity value of the leachate of TFA $(9.24 \mu \mathrm{S} / \mathrm{cm})$ decreased when compared with the corresponding to FA $(40 \mu \mathrm{S} / \mathrm{cm})$, whereas the $\mathrm{pH}$ of both leachates was similar and very alkaline. The treatment with $\mathrm{Na}_{2} \mathrm{CO}_{3}$ reduced the leaching of $\mathrm{Pb}$ from $24 \mathrm{mg} / \mathrm{kg}$ FA to a value of $7.9 \mathrm{mg} / \mathrm{kg}$ TFA, lower than the landfill disposal limit for a non-hazardous landfill, classifying the TFA as non-hazardous material concerning $\mathrm{Pb}$. The leaching of $\mathrm{Zn}$ also decreased although the concentrations in the leachate before and after the treatment were 28.3 and $6.4 \mathrm{mg} / \mathrm{kg}$ for FA and TFA, respectively, corresponding both to non-hazardous materials. The leaching of $\mathrm{Cd}$ and $\mathrm{Cu}$ also decreased, with concentrations in the leachate of $5.6 \cdot 10^{-2}$ and $2.2 \mathrm{mg} / \mathrm{kg}$ FA for the untreated fly ash, and $2.2 \cdot 10^{-2}$ and $0.3 \mathrm{mg} / \mathrm{kg}$ TFA for treated fly ash, respectively. Therefore, concerning these two metals the TFA was classified as unreactive material after treatment. The concentrations of the $\mathrm{Pb}, \mathrm{Zn}, \mathrm{Cu}$ and $\mathrm{Cd}$ in the leachate from TFA were decreased by $67.1,77.4,60.7$ and $86.4 \%$, respectively, compared with the leachate from FA.

The results obtained for heavy metals immobilization in this work are in good agreement with previous studies investigating the effect of accelerated carbonation on fly ash using $\mathrm{CO}_{2}$ (Baciocchi et al., 2009; De Boom et al., 2014; Ecke, 2003; Jianguo et al., 2009; Li et al., 2007; Ni et al., 2017; Wang et al., 2010). The reported effects of $\mathrm{CO}_{2}$ carbonation on the leaching of $\mathrm{Cd}$ were varied whereas it produced a significative reduction in the mobility of $\mathrm{Pb}, \mathrm{Zn}$ and $\mathrm{Cu}$. Therefore, the accelerated carbonation with $\mathrm{CO}_{2}$ treatment decreased the environmental hazard of these residues, allowing to manage the carbonated ash in less stringent landfills in all cases. According to the results, the treatment with a solution of sodium carbonate used in this work caused the same effect concerning the heavy metals of FA.

Nevertheless, the results obtained for the removal of chloride from FA in this work are different from those reported in the literature for the accelerated carbonation. Several authors (Baciocchi et al., 2009; Li et al., 2007; Wang et al., 2010), described that the carbonation with $\mathrm{CO}_{2}$ had a negligible or slight effect on the release of soluble salts as chloride, and the leaching values for carbonated ash were still higher than those for landfill acceptance limits for hazardous waste. Therefore, the advantage of the studied process over the accelerated carbonation processes using $\mathrm{CO}_{2}$ reported in literature lies in the simultaneous immobilization of heavy metals and the removal of soluble salts from the ash. The stabilization procedure succeeded to reduce the environmental hazard of the MSWI FA waste and it allowed to classify the TFA as nonhazardous materials concerning heavy metals and soluble salts.

\subsubsection{Characterization of TFA}

In terms of XRD pattern, the main difference in the mineralogical composition of FA and TFA concerned the disappearance of chlorine compounds $\mathrm{CaCl}(\mathrm{OH}), \mathrm{KCl}$ and $\mathrm{NaCl}$ (Fig. 2 and Table 2).

The DTA/DTG curves for TFA in $\mathrm{N}_{2}$ atmosphere presented three 
main weight events as the FA sample (Fig. 3-A-II). However, the derivative curve was simpler than that of FA, reflecting the effect of the stabilization treatment.

TFA presented a total weight loss of $25 \%$, showing a minor loss ( $2.9 \mathrm{wt} \%$ ) below $300^{\circ} \mathrm{C}$ which was attributed to the physically adsorbed water. The small exothermic peak in the heat flow curve, at around $375^{\circ} \mathrm{C}$, was associated to the previously commented lattice modification of $\gamma-\mathrm{CaSO}_{4}$ for FA. The first main mass decay was around $4 \mathrm{wt} \%$ (maximum about $400{ }^{\circ} \mathrm{C}$ ) and could be associated to the decomposition of $\mathrm{Ca}(\mathrm{OH})_{2}$. The peak associated to portlandite decomposition is the only one between 300 and $500^{\circ} \mathrm{C}$. Therefore, it is concluded that the other two endothermic processes found in this range in FA (i.e. maxima at 450 and $479^{\circ} \mathrm{C}$ ) corresponded to compounds that were not present in TFA.

The second main mass decay represented $11 \mathrm{wt} \%$ in TFA (endothermic event, maximum about $700^{\circ} \mathrm{C}$ ) and could be associated to the decomposition of $\mathrm{CaCO}_{3}$. This maximum occurs at slightly higher temperature than in FA. Probably, the presence of several compounds in FA, such as chlorides, could decrease the temperature of the process (Ramachandran et al., 2002b). The endothermic decomposition event corresponding to calcium hydroxychloride did not appear in TFA, in accordance with the absence of this compound shown by XRD analysis.

Above $700{ }^{\circ} \mathrm{C}$ the thermal behavior of TFA is very different from that observed for FA. The TFA showed a third main event with a maximum around $820^{\circ} \mathrm{C}$ accounting for about $7 \mathrm{wt} \%$. This mass loss finishing at about $900^{\circ} \mathrm{C}$ was quite well defined in the derivative weight curve. Therefore, it could be stated that the mass loss after decomposition of calcite in TFA separate the overlapped events taking place in this range of temperature for FA. That is, the volatilization of alkaline chlorides, $\mathrm{NaCl}$ and $\mathrm{KCl}$, did not occur since they were not present in TFA, in agreement with the XRD results. It means that there are other thermal events, apart from $\mathrm{KCl}$ and $\mathrm{NaCl}$ melting and volatilization, associated to higher temperatures than $700^{\circ} \mathrm{C}$ both in FA and TFA.

To identify these thermal mass loss events, DTA/DTG analysis under air atmosphere were carried out (Fig. 3-B I and 3-B II for FA and TFA, respectively).

Below $550^{\circ} \mathrm{C}$ both analyses showed an interesting behavior. The total weight of the sample decreased as temperature increased but, around $400-450^{\circ} \mathrm{C}$, there was a slight increase in the total mass. Moreover, in both samples, there were exothermic events within the range $400-500^{\circ} \mathrm{C}$ related to the increase of mass. It is clear that in air atmosphere a chemical reaction process was produced in both samples and caused the mass increasing. This event seems to be more complicated for FA, according to its more complex composition, even partially overlapping the endothermic decomposition event (maximum peak around $400^{\circ} \mathrm{C}$ ) of the $\mathrm{Ca}(\mathrm{OH})_{2}$.

The decomposition of $\mathrm{CaCO}_{3}$ was observed in both samples, shifting to a slightly higher temperature in TFA compared to FA as already described in the analysis under $\mathrm{N}_{2}$ atmosphere.

Above $750^{\circ} \mathrm{C}$ the behavior of both samples was different. In FA the total mass decrease steeply and in the corresponding derivative mass curve just an endothermic, not-finished peak was observed, with a maximum at the end of the analysis, around $1000^{\circ} \mathrm{C}$ (the maximum indicates that the process is starting to finish), that could be associated to the melting and vaporization of alkaline chlorides.

Above $750^{\circ} \mathrm{C}$ under air atmosphere TFA did not show any loss weight or thermal event. That is, the endothermic decomposition event observed in this range of temperature for TFA in inert atmosphere did not appear, indicating that the chemical reaction taking place in air atmosphere has removed that compound. Accordingly, with this removal at lower temperatures, only the mass loss due to the volatilization of $\mathrm{NaCl}$ and $\mathrm{KCl}$ was observed in the thermal analysis of $\mathrm{FA}$ in air atmosphere.

As a conclusion, the DTA/DTG analysis under air atmosphere confirmed that FA contained around $7-10 \mathrm{wt} \%$ of an amorphous compound (since it was not present in the XRD pattern of the samples), that was not removed in the stabilization process because it was also present in the TFA sample. That component was oxidized with air at around $400-500{ }^{\circ} \mathrm{C}$ (exothermic event) but it remained under inert atmosphere up to temperatures of around $700^{\circ} \mathrm{C}$ and then it was thermally decomposed following an endothermic event. In a first approach, the amorphous compound present in the FA could be classified as organic matter whose combustion occurs at around $300-500{ }^{\circ} \mathrm{C}$ (Chen et al., 2012; Ecke et al., 2003; Li et al., 2007). The origin of this matter could be the activated carbon used in the incineration plant to remove dioxins and furanes (Zacco et al., 2014).

The organic matter in wastes is usually measured by loss on ignition at $550{ }^{\circ} \mathrm{C}$. However, this method is not adequate in the case of FA due to the very complex composition of the fresh ash. Fig. 3-B-I and 3-B-II showed that the organic matter oxidation event overlaps with others, e.g. the decom position of $\mathrm{Ca}(\mathrm{OH})_{2}$. This fact has been already identify in the literature (Ecke et al., 2003) as conducting to erroneous results up to one order of magnitude for the organic matter, along with the need for a more accurate method to be developed. The results showed that, in certain cases as for TFA, it could be possible to quantify the organic matter by means of thermal analysis done in both oxidizing and inert atmosphere and comparing the results. Therefore, it can be concluded that the decomposition of organic matter changed from about 400 to $500^{\circ} \mathrm{C}$, as an exothermic event in the DTA/DTG analysis in air, to $700-800^{\circ} \mathrm{C}$, as an endothermic event under inert atmosphere.

From XRD and DTA/DTG results, it was observed that during the stabilization process some salts, such as chloride compounds as $\mathrm{CaClOH}, \mathrm{NaCl}$ and $\mathrm{KCl}$, were released into the liquid phase (Waste Liquid). In addition, the absence of all these compounds in TFA justify the higher value of mass loss of the two more relevant peaks, i.e. Ca $(\mathrm{OH})_{2}$ and $\mathrm{CaCO}_{3}$, compared to those for FA.

The solubilization of these salts decreased the chlorides, TDS content and conductivity in the leachate of TFA compared to FA as evidenced by the leaching test results in Table 2. Accordingly, FA was classified as hazardous waste and TFA as non-hazardous waste. The presence of $\mathrm{Ca}\left(\mathrm{SO}_{4}\right)$ in TFA, detected by XRD and DTA/DTG, indicated that some of the sulfates remained in the solid after the stabilization process.

The leachate from TFA presented lower values for the heavy metals than the leachate from FA, being non-hazardous waste (except for the $\mathrm{Pb}$ ) in both cases. However, neither XRD nor DTA/DTG gave information concerning the heavy metals, due to their low concentration in FA. Section 3.4 intended to know whether the heavy metals were transferred into the liquid phase (WL) during the stabilization process or they were retained in the solid phase (TFA).

\subsection{Analysis of the Waste Liquid}

The chemical composition and other analytical parameters of the Waste Liquid were compared with the values of the local regulations in force in the location of the MSWI plant (Tables 5 and 6).

With the analytical results of the Waste Liquid, and the chemical composition of FA showed in Table 1, a mass balance of each element was carried out and the degree of immobilization (DI) of each element in the TFA, expressed as wt $\%$, was calculated (Table 5).

A major part of heavy metals remained almost totally retained in the TFA with DI values higher than $87 \%$, being most of them higher than $98 \%$. In accordance with the XRD, DTA/DTG and conductivity analysis for FA and TFA, the DI of chlorides was negligible. Potassium showed a very low DI value due to the solubilization of alkaline chlorides already discussed. Sulfur was partially retained within the TFA (DI $=49.2 \%)$ in accordance with XRD and DTA/DTG results that showed that sulfur, in the form of anhydrite, was present in TFA. The values for the sodium immobilization were not relevant because this element also comes from the stabilizing agent.

Although there are many studies about the positive effect of the carbonation on the leaching behavior of metals, the mechanisms 
Table 5

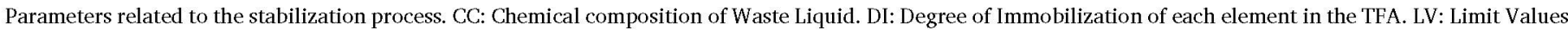
in Waste Liquid, according to the local regulations (Order 130/2003 DOGC 29-5-2003).

\begin{tabular}{|c|c|c|c|c|c|c|c|c|c|c|c|}
\hline & $\mathrm{CC}$ & DI & LV & & $\mathrm{CC}$ & DI & LV & & $\mathrm{CC}$ & DI & $\mathrm{LV}$ \\
\hline & $(\mathrm{mg} / \mathrm{L})$ & $(w t \%)$ & $(\mathrm{mg} / \mathrm{L})$ & & $(\mathrm{mg} / \mathrm{L})$ & $(w t \%)$ & $(\mathrm{mg} / \mathrm{L})$ & & $(\mathrm{mg} / \mathrm{L})$ & $(w t \%)$ & $(\mathrm{mg} / \mathrm{L})$ \\
\hline $\mathrm{Ca}$ & $105 \pm 5$ & 98.4 & - & $\mathrm{P}$ & $<0,020$ & 100 & 50 & $\mathrm{Ni}$ & $<0.020$ & 98.9 & 5 \\
\hline Si & $1.3 \pm 0.1$ & 99.9 & - & $\mathrm{Pb}$ & $0.31 \pm 0.03$ & 98.5 & 1 & $\mathrm{Zr}$ & $<0.020$ & $>98.6$ & - \\
\hline $\mathrm{K}$ & $620 \pm 60$ & 0.5 & - & $\mathrm{Zn}$ & $0.16 \pm 0.03$ & 99.8 & 10 & $\mathrm{Cd}$ & $<0.020$ & $>98.3$ & 0.5 \\
\hline $\mathrm{Al}$ & $0.11 \pm 0.02$ & 100 & 20 & $\mathrm{Ba}$ & $0.098 \pm 0.010$ & 98.8 & 10 & As & $<0.020$ & $>96.0$ & 1 \\
\hline S & $141 \pm 6$ & 49.2 & $*$ & $\mathrm{Sb}$ & $<0.020$ & $>99.7$ & - & $\mathrm{Co}$ & $<0.020$ & $>89.2$ & - \\
\hline $\mathrm{Mg}$ & $<0.020$ & 100 & - & $\mathrm{Sr}$ & $0.45 \pm 0.02$ & 97.9 & - & Mo & - & - & - \\
\hline $\mathrm{Na}$ & 1720 & 50.2 & - & Sn & $<0.050$ & $>99.3$ & 5 & $\mathrm{~W}$ & $<0.020$ & $>87.9$ & - \\
\hline $\mathrm{Fe}$ & $<0.020$ & 100 & 10 & $\mathrm{Cu}$ & $<0.020$ & $>99.7$ & 3 & $\mathrm{Bi}$ & - & - & - \\
\hline $\mathrm{Ti}$ & $<0.010$ & 100 & - & $\mathrm{Mn}$ & $<0.010$ & 99.8 & 2 & & & & \\
\hline $\mathrm{Cl}^{-}$ & $2540 \pm 127$ & 0 & 2500 & $\mathrm{Cr}$ & $0.24 \pm 0.08$ & 95.1 & 3 & & & & \\
\hline
\end{tabular}

* Limit value for sulfates: $1000 \mathrm{mg} / \mathrm{L}$. The content of $\mathrm{S}$ of $141 \mathrm{mg} / \mathrm{L}$ expressed as sulfate will give a value of $425 \mathrm{mg} / \mathrm{L}$.

Table 6

Analysis of Waste Liquid and allowed values for the parameters in the local regulations.

\begin{tabular}{lll}
\hline Parameter & Value & Allowed limits \\
\hline $\mathrm{pH}$ & 12.53 & $6-10$ \\
Suspended solids $(\mathrm{mg} / \mathrm{L})$ & 1025 & 750 \\
Conductivity $(\mathrm{mS} / \mathrm{cm})$ & 59.3 & 6 \\
\hline
\end{tabular}

involved in this stabilization have not been completely elucidated due to the varying and very complex composition of the ash (Sabbas et al., 2003; Wang et al., 2010). It was suggested that the new mineral phase formed through the reaction of the carbonate ions with $\mathrm{Ca}^{2+}$ from the solid could trap or adsorb heavy metals (De Boom et al., 2014; Li et al., 2007). In this work, the $\mathrm{Ca}^{2+}$ could come, at least partially, from the basic salt $\mathrm{CaCl}(\mathrm{OH})$ dissolved in the liquid of the treatment process. Moreover, other works have demonstrated that carbonation causes a change in the solubility-controlling minerals from fresh to treated ash being the metal release controlled by several mineral carbonates (Baciocchi et al., 2009; Jianguo et al., 2009; Ni et al., 2017). After carbonation, the proportion of heavy metals as interchangeable form decreased whereas the proportion in the carbonate fraction increased.

It is concluded that the carbonation process used in this work promoted the formation of metal carbonates. These compounds stabilized the heavy metals in such a way that they did not leach in the experimental conditions tested according to EN 12457-4:2002 Standard, as demonstrated by the leaching test and the measured degree of immobilization of metals.

The Waste Liquid constituted the waste stream of the studied stabilization process. The local regulations affecting the incineration facility that supplied the FA for the present study (Order 130/2003 DOGC 29-5-2003) established the limit values (LV) for liquid waste. The concentration of heavy metals in Waste Liquid was lower than the LV values (Table 5). However, the $\mathrm{pH}$, conductivity, suspended solids and chloride concentration had values higher than those fixed by the regulations. These results were in line with the above described results considering that some soluble compounds, including chlorides, were transferred to the liquid phase during the stabilization process whereas the metals remained in the stabilized fly ash. The wastewater of the stabilization process must be treated for disposal or used as process water within the incineration facilities.

\section{Conclusions}

The studied fly ash exceeded the limits for hazardous waste landfills. The stabilization procedure described in the present work reduced the environmental hazard of the MSWI FA waste and the TFA was classified as non-hazardous waste.
The main difference in the mineralogical composition of the FA and TFA was the removal of soluble chlorine compounds. $96.8 \mathrm{wt} \%$ of $\mathrm{Cl}^{-}$ ions were removed from FA regardless of the solid/liquid ratio and concentration of sodium carbonate, with a contact time of $5 \mathrm{~min}$, demonstrating the leaching of chloride ions was high and very fast. The carbonation reaction led to significant reductions in $\mathrm{Pb}, \mathrm{Zn}, \mathrm{Cu}$ and $\mathrm{Cd}$ mobility, decreasing the concentration by $67.1,77.4,60.7$ and $86.4 \%$, respectively, with respect to the leachate from FA. The mass balance showed that most of the heavy metals remained in TFA with degrees of immobilization higher than $87 \%$. The stabilization process promoted the formation of insoluble, non-leachable salts as metal carbonates, leading to an improvement in the stability of the heavy metals within the range studied.

The method presented a double function in a single step: separation of chlorides and immobilization of heavy metals. This mixed process is promising at industrial level and presented clear advantages over the carbonation process using $\mathrm{CO}_{2}$, i.e. (i) simplicity by working with liquid phase instead of a gas stream; (ii) the costs of a salt produced at industrial level as sodium carbonate are lower than that of pure $\mathrm{CO}_{2}$ and/ or the method does not depend on the use of the flue gas-derived $\mathrm{CO}_{2}$ from an industrial facility; (iii) the reaction time is very short compared with the corresponding values reported for $\mathrm{CO}_{2}$ carbonation in liquid phase; (iv) the stabilization method operates at room temperature and atmospheric pressure.

The improvement of the environmental impacts of the TFA compared to FA could open new opportunities for their controlled reuse, for example as secondary raw material in civil engineering.

\section{Acknowledgements}

This work was supported by Valoriza Servicios Medioambientales (Sacyr Group). 